
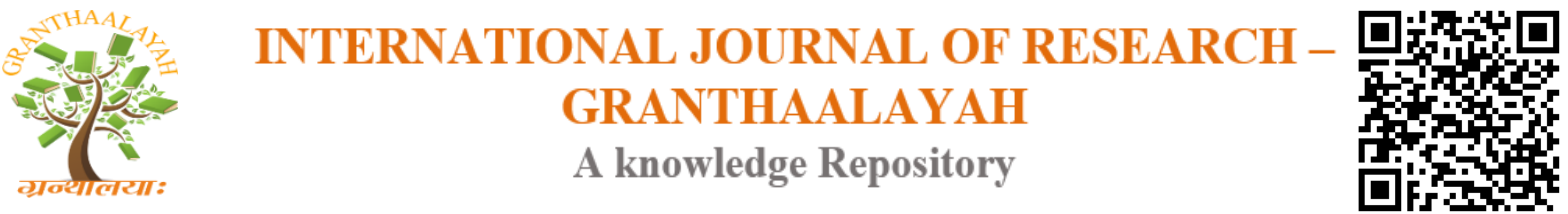

Science

\title{
SUPERLATIVE ALGORITHM FOR REDUCTION OF ACTIVE POWER LOSS
}

\author{
Dr.K.Lenin *1 \\ ${ }^{* 1}$ Professor, Department of EEE Prasad V.Potluri Siddhartha Institute of Technology, Kanuru, \\ Vijayawada, Andhra Pradesh -520007, India
}

\begin{abstract}
This paper proposes Spinner Dolphin Algorithm (SDA) for solving optimal reactive power problem. Echolocation is the genetic sonar used by Spinner dolphin \& it used by few kinds of other animals for direction-finding, hunting in diverse environments. This ability of Spinner dolphin is imitated in this paper to develop a new-fangled procedure for solving optimal reactive power problem. Spinner Dolphin Algorithm (SDA) takes reward of the overriding rules and outperforms many vigorous optimization methods. The new-fangled approach SDA leads to exceptional results with small computational efforts. In order to evaluate the efficiency of the proposed algorithm, it has been tested Standard IEEE 57,118 bus systems and compared to other specified algorithms. Simulation result show that Spinner Dolphin Algorithm (SDA) is advanced to other algorithms in reducing the real power loss and voltage profiles are within the limits.
\end{abstract}

Keywords: Spinner Dolphin Algorithm; Optimization; Optimal Reactive Power; Transmission Loss.

Cite This Article: Dr.K.Lenin. (2017). "SUPERLATIVE ALGORITHM FOR REDUCTION OF ACTIVE POWER LOSS." International Journal of Research - Granthaalayah, 5(10), 101-111. https://doi.org/10.29121/granthaalayah.v5.i10.2017.2287.

\section{Introduction}

Optimal reactive power problem minimizes the real power loss and bus voltage deviation. Various mathematical techniques like the gradient method [1-2], Newton method [3] and linear programming [4-7] have been adopted to solve the optimal reactive power dispatch problem. Both the gradient and Newton methods have the complexity in managing inequality constraints. If linear programming is applied then the input- output function has to be uttered as a set of linear functions which mostly lead to loss of accuracy. The problem of voltage stability and collapse play a major role in power system planning and operation [8]. Global optimization has received extensive research awareness, and a great number of methods have been applied to solve this problem. Evolutionary algorithms such as genetic algorithm have been already proposed to solve the reactive power flow problem $[9,10]$. Evolutionary algorithm is a heuristic approach used for minimization problems by utilizing nonlinear and non-differentiable 
continuous space functions. In [11], Genetic algorithm has been used to solve optimal reactive power flow problem. In [12], Hybrid differential evolution algorithm is proposed to improve the voltage stability index. In [13] Biogeography Based algorithm is projected to solve the reactive power dispatch problem. In [14], a fuzzy based method is used to solve the optimal reactive power scheduling method. In [15], an improved evolutionary programming is used to solve the optimal reactive power dispatch problem. In [16], the optimal reactive power flow problem is solved by integrating a genetic algorithm with a nonlinear interior point method. In [17], a pattern algorithm is used to solve ac-dc optimal reactive power flow model with the generator capability limits. In [18], F. Capitanescu proposes a two-step approach to evaluate Reactive power reserves with respect to operating constraints and voltage stability. In [19], a programming based approach is used to solve the optimal reactive power dispatch problem. In [20], A. Kargarian et al present a probabilistic algorithm for optimal reactive power provision in hybrid electricity markets with uncertain loads. Spinner Dolphin Algorithm (SDA) a new optimization technique $\&$ is used to solve the reactive power problem. This method mimics strategy used by dolphins for their hunting procedure. Dolphins create a type of voice [21] called sonar to trace the target. By doing this dolphin alter sonar to alter the target and its position. Echolocation is the genetic sonar used by Spinner dolphin \& it used by few kinds of other animals for direction-finding, hunting in diverse environments. This ability of Spinner dolphin is imitated in this paper to develop a new-fangled procedure for solving optimal reactive power problem. Spinner Dolphin Algorithm (SDA) takes reward of the overriding rules and outperforms many vigorous optimization methods. The new-fangled approach SDA leads to exceptional results with small computational efforts. In order to evaluate the efficiency of the proposed algorithm, it has been tested Standard IEEE 57,118 bus systems and compared to other specified algorithms. Simulation result show that Spinner Dolphin Algorithm (SDA) is advanced to other algorithms in reducing the real power loss and voltage profiles are within the limits.

\section{Problem Formulation}

The optimal power flow problem is treated as a general minimization problem with constraints, and can be mathematically written in the following form:

Minimize $\mathrm{f}(\mathrm{x}, \mathrm{u})$

Subject to $\mathrm{g}(\mathrm{x}, \mathrm{u})=0$

And

$\mathrm{h}(\mathrm{x}, \mathrm{u}) \leq 0$

Where $f(x, u)$ is the objective function. $g(x . u)$ and $h(x, u)$ are respectively the set of equality and inequality constraints. $\mathrm{x}$ is the vector of state variables, and $\mathrm{u}$ is the vector of control variables.

The state variables are the load buses (PQ buses) voltages, angles, the generator reactive powers and the slack active generator power:

$\mathrm{x}=\left(\mathrm{P}_{\mathrm{g} 1}, \theta_{2}, \ldots, \theta_{\mathrm{N}}, \mathrm{V}_{\mathrm{L} 1}, ., \mathrm{V}_{\mathrm{LNL}}, \mathrm{Q}_{\mathrm{g} 1}, \ldots, \mathrm{Q}_{\mathrm{gng}}\right)^{\mathrm{T}}$

The control variables are the generator bus voltages, the shunt capacitors/reactors and the transformers tap-settings: 
$\mathrm{u}=\left(\mathrm{V}_{\mathrm{g}}, \mathrm{T}, \mathrm{Q}_{\mathrm{c}}\right)^{\mathrm{T}}$

Or

$\mathrm{u}=\left(\mathrm{V}_{\mathrm{g} 1}, \ldots, \mathrm{V}_{\mathrm{gng}}, \mathrm{T}_{1}, \ldots, \mathrm{T}_{\mathrm{Nt}}, \mathrm{Q}_{\mathrm{c} 1}, \ldots, \mathrm{Q}_{\mathrm{cNc}}\right)^{\mathrm{T}}$

Where ng, nt and nc are the number of generators, number of tap transformers and the number of shunt compensators respectively.

\section{Objective Function}

\subsection{Active Power Loss}

The objective of the reactive power dispatch is to minimize the active power loss in the transmission network, which can be described as follows:

$F=P L=\sum_{k \in N b r} g_{k}\left(V_{i}^{2}+V_{j}^{2}-2 V_{i} V_{j} \cos \theta_{i j}\right)$

Or

$F=P L=\sum_{i \in N g} P_{g i}-P_{d}=P_{g s l a c k}+\sum_{i \neq s l a c k}^{N g} P_{g i}-P_{d}$

Where $g_{k}$ : is the conductance of branch between nodes $i$ and $j$, Nbr: is the total number of transmission lines in power systems. $\mathrm{P}_{\mathrm{d}}$ : is the total active power demand, $\mathrm{P}_{\text {gi }}$ : is the generator active power of unit $i$, and $\mathrm{P}_{\text {gsalck: }}$ is the generator active power of slack bus.

\subsection{Voltage Profile Improvement}

For minimizing the voltage deviation in PQ buses, the objective function becomes:

$F=P L+\omega_{v} \times V D$

Where $\omega_{\mathrm{v}}$ : is a weighting factor of voltage deviation.

VD is the voltage deviation given by:

$V D=\sum_{i=1}^{N p q}\left|V_{i}-1\right|$

\subsection{Equality Constraint}

The equality constraint $\mathrm{g}(\mathrm{x}, \mathrm{u})$ of the Optimal reactive power problem is represented by the power balance equation, where the total power generation must cover the total power demand and the power losses:

$P_{G}=P_{D}+P_{L}$

This equation is solved by running Newton Raphson load flow method, by calculating the active power of slack bus to determine active power loss. 


\subsection{Inequality Constraints}

The inequality constraints $\mathrm{h}(\mathrm{x}, \mathrm{u})$ reflect the limits on components in the power system as well as the limits created to ensure system security. Upper and lower bounds on the active power of slack bus, and reactive power of generators:

$P_{\text {gslack }}^{\min } \leq P_{\text {gslack }} \leq P_{\text {gslack }}^{\max }$

$Q_{g i}^{\min } \leq Q_{g i} \leq Q_{g i}^{\max }, i \in N_{g}$

Upper and lower bounds on the bus voltage magnitudes:

$V_{i}^{\min } \leq V_{i} \leq V_{i}^{\max }, i \in N$

Upper and lower bounds on the transformers tap ratios:

$T_{i}^{\min } \leq T_{i} \leq T_{i}^{\max }, i \in N_{T}$

Upper and lower bounds on the compensators reactive powers:

$Q_{c}^{\min } \leq Q_{c} \leq Q_{C}^{\max }, i \in N_{C}$

Where $\mathrm{N}$ is the total number of buses, $\mathrm{N}_{\mathrm{T}}$ is the total number of Transformers; $\mathrm{N}_{\mathrm{c}}$ is the total number of shunt reactive compensators.

\section{Spinner Dolphin in Natural World}

The word "echolocation" was initiated by Griffin [22] to explain the capability of flying bats to locate obstacles and preys by listening to echoes recurring from high-frequency clicks that they emitted. The finest studied echolocation in nautical mammals is the dolphins [23]. A dolphin is gifted to generate sounds in the form of clicks. Rate of recurrence of these clicks is superior to that of the sounds used for communication and it differs between species. As soon as the sound strikes an object, some of the power of the sound-wave is reflected back towards the dolphin. Instantaneously an echo is received; the dolphin generates one more click. The time fall between click and echo enables the dolphin to appraise the distance from the object. The altering power of the signal as it is received on the two sides of the dolphin's head enable to evaluate the way. By incessantly emitting clicks and receiving echoes in this technique, the dolphin can follow objects and home in on them [25]. The clicks are directional. For echolocation, frequently happening in a short sequence called a click rate. The click rate increases when close to an object concentration [24]. Although bats also utilize echolocation, however, they differ from dolphins in their sonar scheme. Bats use their sonar scheme at little ranges around 3-4 m, whereas dolphins can sense their targets at ranges varying more than a hundred meters. A lot of bats hunt for insects that dash rapidly to and fro and making it very dissimilar from the runaway behaviour of a fish chased by dolphin. The pace of sound in air is about one fifth of that of water, thus the information transmit rate for the period of sonar transmission of bats is much shorter than that of the dolphins. 


\section{Spinner Dolphin Echolocation Process}

Spinner Dolphins primarily investigate all around the search space to discover the prey. The moment a dolphin approaches the target, the animal confine its search, and incrementally increases its clicks in order to concentrate on the location. The method simulates dolphin echolocation by restraining its exploration relative to the distance from the target. Prior to starting, search space should be sorted out by using the following regulation:

Search space order: For every variable to be optimized during the procedure, sort alternatives of the search space in an uphill or downhill order. If alternatives take account of more than one characteristic, then carry out ordering according to the most significant one. Using this technique, for variable $j$, vector $A_{j}$ of length $L A_{j}$ is shaped which contains all probable alternatives for the $\mathrm{jth}$ variable putting these vectors subsequently to each other, as the columns of a matrix, the Matrix Alternatives $\mathrm{MA}_{\mathrm{N} N \mathrm{~N}}$ is produced, in which MA is $\max \left(\mathrm{LA}_{\mathrm{j}}\right)_{\mathrm{j}=1: \mathrm{NV}}$, with $\mathrm{NV}$ being the number of variables. Furthermore, a curve according to which the convergence factor must change during the optimization procedure should be assigned. Here, the change of convergence $(\mathrm{CF})$ is considered as

$P P\left(L O O P_{i}\right)=P P_{i}+\left(1-P P_{1}\right) \frac{\text { LOOP }_{i}^{\text {power }}-1}{\left(\text { LOOPSNumber }^{\text {power }}-1\right.}$

$\mathrm{PP}$ is the predefined probability, $\mathrm{PP}_{1}$ the convergence factor of the first loop in which the answers are selected randomly, Loop in $_{i}$ the number of the current loop.

Procedure of Spinner Dolphin Algorithm (SDA) as follows:

1. Start NL locations for a dolphin arbitrarily. This step enclose creating $\mathrm{L}_{\mathrm{NL}+\mathrm{NV}}$ matrix, in which NL is the number of locations and NV is the number of variables.

2. Compute the PP of the loop using Eq. (17).

3. Calculate the fitness of each location.

4. Calculate the accumulative fitness according to dolphin rules as follows.

- for $\mathrm{i}=1$ to the number of locations

- for $\mathrm{j}=1$ to the number of variables

- Find the position of L (i,j) in jth column of the Alternatives matrix and name it as $A$. for $k=-R_{e}$ to $R_{e}$.

$A F_{(A+K) j}=\frac{1}{R_{e}} *\left(R_{e}-|k|\right)$ Fitness $i+A F_{(A+K) j}$

Where $A F(A+k) j$ is the accumulative fitness of the $(A+k)$ th alternative to be chosen for the $j$ th variable, $R_{e}$ is the effective radius in which accumulative fitness of the alternative A's neighbours are affected from its fitness. Fitness (i) is the fitness of location i. It should be added that for alternatives close to edges (where $A+k$ is not a valid; $A+k<0$ or $A+k>L A_{j}$ ), the $A F$ is calculated using a reflective characteristic. 
In order to hand out the option much evenly in the search space, a small value of $\varepsilon$ is added to all the arrays as $\mathrm{AF}=\mathrm{AF}+\varepsilon$. Here, e should be selected according to the method the fitness is defined. It is superior to be less than the minimum value achieved for the fitness.

Find the top location of this loop and name it "The best Location". Find the alternatives allocated to the variables of the top location, and let their AF be equal to zero. And it can be defined as follows

- for $\mathrm{j}=1$ : Number of variables

- for $\mathrm{i}=1$ : Number of alternatives

- $\quad$ if $\mathrm{i}=$ The best location(j)

$A F_{i j}=0$

For variable $\mathrm{j}_{(\mathrm{j}=1 \mathrm{toNV})}$, compute the probability of choosing alternative $\mathrm{i}_{(\mathrm{i}=1 \text { toALj) }}$, according to the following relationship:

$$
P_{i j}=\frac{A F_{i j}}{\sum_{i=1}^{L A j} A F_{i j}}
$$

Allocate a probability equal to PP to all alternatives chosen for all variables of the best location and dedicate rest of the probability to the other alternatives according to the following formula:

- for $\mathrm{j}=1$ : Number of variables

- for $\mathrm{i}=1$ : Number of alternatives

- $\quad$ if $\mathrm{i}=$ The best location $(\mathrm{j})$

$P_{i j}=P P$

Else

$P_{i j}=(1-P P) P_{i j}$

Compute the subsequently step locations according to the probabilities assigned to each alternative. Replicate Steps ii-vi as many times as the Loops Number.

\subsection{Spinner Dolphin Algorithm (SDA) For Solving Optimal Reactive Power Problem}

Step a. instigates the description of the problem and choose the positions of dolphin randomly. Step b. Compute the fitness for every location.

Step c. Compute the accumulative fitness by devoting the intended fitness to the alternatives chosen for every dimension and its neighbours according to the dolphin regulations and find the best location.

Step d. Assign the possibility of the most excellent location equal to the predefined possibility value in the current loop and share out rest of the probability between other alternatives according to the premeditated accumulative fitness's.

Step e. Choose next loop locations according to the designed probability.

Step f. Is terminating criterion reached- if yes stop or go to step b. 


\section{Simulation Results}

At first Spinner Dolphin Algorithm (SDA) has been tested in standard IEEE-57 bus power system. The reactive power compensation buses are 18, 25 and 53. Bus 2, 3, 6, 8, 9 and 12 are PV buses and bus 1 is selected as slack-bus. The system variable limits are given in Table 1. The preliminary conditions for the IEEE-57 bus power system are given as follows:

$\mathrm{P}_{\text {load }}=12.120$ p.u. $\mathrm{Q}_{\text {load }}=3.068$ p.u.

The total initial generations and power losses are obtained as follows:

$\sum P_{G}=12.474$ p.u. $\sum Q_{G}=3.3166$ p.u.

$\mathrm{P}_{\text {loss }}=0.25870$ p.u. $\mathrm{Q}_{\text {loss }}=-1.2072$ p.u.

Table 2 shows the various system control variables i.e. generator bus voltages, shunt capacitances and transformer tap settings obtained after optimization which are within the acceptable limits. In Table 3, shows the comparison of optimum results obtained from proposed methods with other optimization techniques. These results indicate the robustness of proposed approaches for providing better optimal solution in case of IEEE-57 bus system.

Table 1: Variable Limits

\begin{tabular}{|c|c|c|c|c|c|c|c|}
\hline \multicolumn{7}{|c|}{ Reactive Power Generation Limits } \\
\hline Bus no & 1 & 2 & 3 & 6 & 8 & 9 & 12 \\
\hline Qgmin & -1.4 & -.015 & -.02 & -0.04 & -1.3 & -0.03 & -0.4 \\
\hline Qgmax & 1 & 0.3 & 0.4 & 0.21 & 1 & 0.04 & 1.50 \\
\hline \multicolumn{7}{|c|}{ Voltage And Tap Setting Limits } \\
\hline vgmin & Vgmax & vpqmin & Vpqmax & tkmin & tkmax & \\
\hline 0.9 & 1.0 & 0.91 & 1.05 & 0.9 & 1.0 & \\
\hline \multicolumn{7}{|c|}{ Shunt Capacitor Limits } \\
\hline Bus no & 18 & \multicolumn{7}{|c|}{25} & 53 \\
\hline Qcmin & 0 & \multicolumn{3}{|c|}{0} \\
\hline Qcmax & 10 & 5.2 & 6.1 \\
\hline
\end{tabular}

Table 2: Control variables obtained after optimization

\begin{tabular}{|l|l|}
\hline Control Variables & SDA \\
\hline V1 & 1.10 \\
\hline V2 & 1.030 \\
\hline V3 & 1.032 \\
\hline V6 & 1.024 \\
\hline V8 & 1.026 \\
\hline V9 & 1.008 \\
\hline V12 & 1.010 \\
\hline
\end{tabular}




\begin{tabular}{|l|l|}
\hline Qc18 & 0.0662 \\
\hline Qc25 & 0.200 \\
\hline Qc53 & 0.0474 \\
\hline T4-18 & 1.006 \\
\hline T21-20 & 1.048 \\
\hline T24-25 & 0.860 \\
\hline T24-26 & 0.872 \\
\hline T7-29 & 1.054 \\
\hline T34-32 & 0.876 \\
\hline T11-41 & 1.018 \\
\hline T15-45 & 1.030 \\
\hline T14-46 & 0.910 \\
\hline T10-51 & 1.020 \\
\hline T13-49 & 1.060 \\
\hline T11-43 & 0.910 \\
\hline T40-56 & 0.900 \\
\hline T39-57 & 0.950 \\
\hline T9-55 & 0.950 \\
\hline
\end{tabular}

Table 3: Comparison results

\begin{tabular}{|l|l|l|l|l|}
\hline S.No. & Optimization Algorithm & Finest Solution & Poorest Solution & Normal Solution \\
\hline 1 & NLP [26] & 0.25902 & 0.30854 & 0.27858 \\
\hline 2 & CGA [26] & 0.25244 & 0.27507 & 0.26293 \\
\hline 3 & AGA [26] & 0.24564 & 0.26671 & 0.25127 \\
\hline 4 & PSO-w [26] & 0.24270 & 0.26152 & 0.24725 \\
\hline 5 & PSO-cf [26] & 0.24280 & 0.26032 & 0.24698 \\
\hline 6 & CLPSO [26] & 0.24515 & 0.24780 & 0.24673 \\
\hline 7 & SPSO-07 [26] & 0.24430 & 0.25457 & 0.24752 \\
\hline 8 & L-DE [26] & 0.27812 & 0.41909 & 0.33177 \\
\hline 9 & L-SACP-DE [26] & 0.27915 & 0.36978 & 0.31032 \\
\hline 10 & L-SaDE [26] & 0.24267 & 0.24391 & 0.24311 \\
\hline 11 & SOA [26] & 0.24265 & 0.24280 & 0.24270 \\
\hline 12 & LM [27] & 0.2484 & 0.2922 & 0.2641 \\
\hline 13 & MBEP1 [27] & 0.2474 & 0.2848 & 0.2643 \\
\hline 14 & MBEP2 [27] & 0.2482 & 0.283 & 0.2592 \\
\hline 15 & BES100 [27] & 0.2438 & 0.263 & 0.2541 \\
\hline 16 & BES200 [27] & 0.3417 & 0.2486 & 0.2443 \\
\hline 17 & Proposed SDA & 0.22064 & 0.23010 & 0.22202 \\
\hline
\end{tabular}

Then Spinner Dolphin Algorithm (SDA) has been tested in standard IEEE 118-bus test system [28].The system has 54 generator buses, 64 load buses, 186 branches and 9 of them are with the tap setting transformers. The limits of voltage on generator buses are $0.95-1.1$ per-unit., and on load buses are $0.95-1.05$ per-unit. The limit of transformer rate is $0.9-1.1$, with the changes step of 0.025 . The limitations of reactive power source are listed in Table 4, with the change in step of 0.01 . 
Table 4: Limitation of reactive power sources

\begin{tabular}{|l|l|l|l|l|l|l|l|}
\hline BUS & 5 & 34 & 37 & 44 & 45 & 46 & 48 \\
\hline QCMAX & 0 & 14 & 0 & 10 & 10 & 10 & 15 \\
\hline QCMIN & -40 & 0 & -25 & 0 & 0 & 0 & 0 \\
\hline BUS & 74 & 79 & 82 & 83 & 105 & 107 & 110 \\
\hline QCMAX & 12 & 20 & 20 & 10 & 20 & 6 & 6 \\
\hline QCMIN & 0 & 0 & 0 & 0 & 0 & 0 & 0 \\
\hline
\end{tabular}

The statistical comparison results of 50 trial runs have been list in Table 5 and the results clearly show the better performance of proposed Spinner Dolphin Algorithm (SDA) in reducing the real power loss.

Table 5: Comparison results

\begin{tabular}{|l|l|l|l|l|}
\hline $\begin{array}{l}\text { Active } \\
\text { power loss } \\
\text { (MW) }\end{array}$ & $\begin{array}{l}\text { BBO } \\
{[\mathbf{2 9}]}\end{array}$ & $\begin{array}{l}\text { ILSBBO/ } \\
\text { strategy1 } \\
\text { [29] }\end{array}$ & $\begin{array}{l}\text { ILSBBO/ } \\
\text { strategy1 } \\
\text { [29] }\end{array}$ & $\begin{array}{l}\text { Proposed } \\
\text { SDA }\end{array}$ \\
\hline Min & 128.77 & 126.98 & 124.78 & 116.98 \\
\hline Max & 132.64 & 137.34 & 132.39 & 122.26 \\
\hline Average & 130.21 & 130.37 & 129.22 & 118.12 \\
\hline
\end{tabular}

\section{Conclusion}

In this paper Spinner Dolphin Algorithm (SDA) successfully solved optimal reactive power problem. The new-fangled approach SDA leads to exceptional results with small computational efforts. In order to evaluate the efficiency of the proposed Spinner Dolphin Algorithm (SDA), it has been tested Standard IEEE 57,118 bus systems and compared to other specified algorithms. Simulation result show that Spinner Dolphin Algorithm (SDA) is advanced to other algorithms in reducing the real power loss and particularly voltage profiles are within the limits.

\section{References}

[1] O.Alsac,and B. Scott, "Optimal load flow with steady state security", IEEE Transaction. PAS 1973, pp. 745-751.

[2] Lee K Y ,Paru Y M , Oritz J L -A united approach to optimal real and reactive power dispatch , IEEE Transactions on power Apparatus and systems 1985: PAS-104 : 1147-1153

[3] A.Monticelli , M .V.F Pereira , and S. Granville , "Security constrained optimal power flow with post contingency corrective rescheduling", IEEE Transactions on Power Systems :PWRS-2, No. 1, pp.175-182.,1987.

[4] Deeb N, Shahidehpur S.M, Linear reactive power optimization in a large power network using the decomposition approach. IEEE Transactions on power system 1990: 5(2) : 428-435

[5] E. Hobson ,'Network consrained reactive power control using linear programming, 'IEEE Transactions on power systems PAS -99 (4) ,pp 868=877, 1980

[6] K.Y Lee, Y.M Park, and J.L Oritz, "Fuel -cost optimization for both real and reactive power dispatches", IEE Proc; 131C, (3), pp.85-93. 
[7] M.K. Mangoli, and K.Y. Lee, "Optimal real and reactive power control using linear programming", Electr.Power Syst.Res, Vol.26, pp.1-10,1993.

[8] C.A. Canizares, A.C.Z.de Souza and V.H. Quintana, "Comparison of performance indices for detection of proximity to voltage collapse," vol. 11. no.3, pp.1441-1450, Aug 1996.

[9] K.Anburaja, "Optimal power flow using refined genetic algorithm", Electr.Power Compon.Syst, Vol. 30, 1055-1063, 2002.

[10] D. Devaraj, and B. Yeganarayana, "Genetic algorithm based optimal power flow for security enhancement", IEE proc-Generation.Transmission and. Distribution; 152, 6 November 2005.

[11] A.Berizzi, C. Bovo, M. Merlo, and M. Delfanti, "A ga approach to compare orpf objective functions including secondary voltage regulation," Electric Power Systems Research, vol. 84, no. 1, pp. $187-194,2012$.

[12] C.-F. Yang, G. G. Lai, C.-H. Lee, C.-T. Su, and G. W. Chang, "Optimal setting of reactive compensation devices with an improved voltage stability index for voltage stability enhancement," International Journal of Electrical Power and Energy Systems, vol. 37, no. 1, pp. $50-57,2012$.

[13] P. Roy, S. Ghoshal, and S. Thakur, "Optimal var control for improvements in voltage profiles and for real power loss minimization using biogeography based optimization," International Journal of Electrical Power and Energy Systems, vol. 43, no. 1, pp. 830 - 838, 2012.

[14] B. Venkatesh, G. Sadasivam, and M. Khan, "A new optimal reactive power scheduling method for loss minimization and voltage stability margin maximization using successive multi-objective fuzzy lp technique," IEEE Transactions on Power Systems, vol. 15, no. 2, pp. $844-851$, may 2000.

[15] W. Yan, S. Lu, and D. Yu, "A novel optimal reactive power dispatch method based on an improved hybrid evolutionary programming technique," IEEE Transactions on Power Systems, vol. 19, no. 2, pp. 913 - 918, may 2004.

[16] W. Yan, F. Liu, C. Chung, and K. Wong, "A hybrid genetic algorithminterior point method for optimal reactive power flow," IEEE Transactions on Power Systems, vol. 21, no. 3, pp. 1163 1169, aug. 2006.

[17] J. Yu, W. Yan, W. Li, C. Chung, and K. Wong, "An unfixed piecewiseoptimal reactive powerflow model and its algorithm for ac-dc systems," IEEE Transactions on Power Systems, vol. 23, no. 1 , pp. $170-176$, feb. 2008.

[18] F. Capitanescu, "Assessing reactive power reserves with respect to operating constraints and voltage stability," IEEE Transactions on Power Systems, vol. 26, no. 4, pp. 2224-2234, nov. 2011.

[19] Z. Hu, X. Wang, and G. Taylor, "Stochastic optimal reactive power dispatch: Formulation and solution method," International Journal of Electrical Power and Energy Systems, vol. 32, no. 6, pp. $615-621,2010$.

[20] A.Kargarian, M. Raoofat, and M. Mohammadi, "Probabilistic reactive power procurement in hybrid electricity markets with uncertain loads," Electric Power Systems Research, vol. 82, no. 1, pp. $68-80,2012$.

[21] A.Kaveh , N. Farhoudi A new optimization method: Dolphin echolocation, Advances in Engineering Software 59 (2013) 53-70.

[22] Griffin DR. Listening in the dark: the acoustic orientation of bats and men. New Haven (CT), Cambridge (MA): Yale University Press, Biological Laboratories, Harvard University; 1958. p. 413.

[23] Au WWL. The sonar of dolphins. New York: Springer; 1993.

[24] May J. The greenpeace book of dolphins. Greenpeace Communications Ltd.; 1990.

[25] Thomas JA, Moss CF, Vater M. Echolocation in bats and dolphins. University of Chicago Press; 2002. 
[26] Chaohua Dai, Weirong Chen, Yunfang Zhu, and Xuexia Zhang, "Seeker optimization algorithm for optimal reactive power dispatch," IEEE Trans. Power Systems, Vol. 24, No. 3, August 2009, pp. 1218-1231.

[27] J. R. Gomes and 0. R. Saavedra, "Optimal reactive power dispatch using evolutionary computation: Extended algorithms," IEE Proc.-Gener. Transm. Distrib.. Vol. 146, No. 6. Nov. 1999.

[28] IEEE, "The IEEE 30-bus test system and the IEEE 118-test system", (1993), http://www.ee.washington.edu/trsearch/pstca/.

[29] Jiangtao Cao, Fuli Wang and Ping Li, "An Improved Biogeography-based Optimization Algorithm for Optimal Reactive Power Flow" International Journal of Control and Automation Vol.7, No.3 (2014), pp.161-176.

*Corresponding author.

E-mail address: gklenin@gmail.com 